\title{
Use of psychoactive and antiepileptic drugs: guidelines for pediatricians
}

\author{
Gibsi P. Rocha1, Bianca H. Batista², Magda L. Nunes ${ }^{3}$
}

\begin{abstract}
Objective: To review the guidelines for the use of psychoactive and antiepileptic drugs in childhood and adolescence.

Sources of data: Literature review.

Summary of the findings: The clinical indications, dosage and side effects of psychoactive and antiepileptic drugs are presented. The use of psychoactive drugs is increasing due to the release of new drugs and to the better understanding of emotional disorders in children and adolescents.

Conclusions: The use of antiepileptic and psychoactive drugs in childhood requires extensive knowledge concerning pharmacokinetics and deleterious side effects. An adequate choice of drugs is essential to ensure a successful treatment.

J Pediatr (Rio J). 2004;80(2 Suppl):S45-S55: Psychoactive drugs, antiepileptic drugs, epilepsy, psychiatric diseases, childhood, adolescence, psychopharmacology.
\end{abstract}

\section{Psychoactive drugs}

The use of psychotropic drugs to treat children and adolescents has become increasingly frequent due to the greater availability of new drugs and to the remarkable insight into the diagnosis of emotional disorders among these patients.

When deciding which psychotropic drug to treat a given patient with, both diagnosis and target symptoms have to be considered. It is essential that the diagnosis be accurate and that target symptoms be identified and quantified. These symptoms should be severe enough to the extent of interfering with patients' activities and development. In some cases, the selection of the

1. Associate professor, School of Medicine, Pontifícia Universidade Católica do Rio Grande do Sul (PUCRS), Porto Alegre, RS, Brazil.

2. Resident physician, Service of Neurology, Hospital São Lucas, Pontifícia Universidade Católica do Rio Grande do Sul (PUCRS), Porto Alegre, RS, Brazil.

3. Associate professor, School of Medicine, Pontifícia Universidade Católica do Rio Grande do Sul (PUCRS), Porto Alegre, RS, Brazil. appropriate medication may be easy, as the same drug can be used to treat the underlying disease and target symptoms efficiently. For instance, antipsychotics are used to treat schizophrenia and its target symptoms (hallucinations, delusions, thought disorders). However, this rationale does not apply to hyperactivity, a symptom that is observed in numerous psychiatric disorders. Psychiatrists should make the diagnosis of attention deficit hyperactivity disorder before prescribing methylphenidate. The use of methylphenidate in patients with schizophrenia in remission, bipolar disorder, or borderline disorder may produce psychotic symptoms. ${ }^{1}$

\section{Pharmacokinetics in children and adolescents}

Pharmacokinetics refers to the biological process that causes drug concentrations in body tissues and fluids to change. The changes in absorption, distribution, metabolism and excretion of drugs during the growth period may affect their target tissue concentrations. Children and 
adolescents often require higher doses per body weight than adults to obtain equivalent therapeutic results and serum levels. This occurs due to more rapid liver metabolism and increased glomerular filtration rate. ${ }^{2}$

\section{Basic principles}

A thorough clinical history and physical and neurological examination should be performed in order to rule out somatic factors that might contribute to psychiatric symptoms. The following laboratory tests are recommended: complete blood count; serum levels of urea, creatinine, sodium, potassium, chlorine, calcium, carbon dioxide and phosphate, in addition to liver function tests. A baseline electrocardiogram (ECG) should be performed before the administration of tricyclic antidepressants and lithium, since these drugs may cause cardiac side effects. An electroencephalogram (EEG) is also recommended in selected cases (epileptic patients or those at high risk for epilepsy) before the use of antipsychotics, antidepressants and lithium, since these drugs may lower the seizure threshold. Thyroid function tests are indicated before the administration of lithium, since hypothyroidism may result from its use. Cardiac arrhythmias induced by tricyclic agents may be aggravated by a previously abnormal thyroid function.

When choosing psychotropic drugs, it is recommended that a standard medication be initially given based on patient's age, diagnosis, and target symptoms. The following aspects are also important: selection of a drug that produces fewer serious side effects, patient's previous response to that drug, response of family members to that drug, and the physician's own experience with that psychotropic drug.

Low doses should be initially used, so that the recommended therapeutic dose is not exceeded for some patients, including those children and adolescents who are responsive to lower doses. The dose can be escalated until one of the following situations is observed: a) satisfactory reduction of symptoms; b) the upper limit of the recommended dose range has been reached; c) occurrence of side effects that do not allow dose escalation; or d) stabilization or worsening of symptoms with additional dose escalation after reasonable improvement of target symptoms. ${ }^{3}$

\section{Major psychiatric disorders requiring drug therapy}

Bipolar affective disorder (ICD-10 F 31)/bipolar disorder (DSM IV 296.0)

The use of mood stabilizers to treat children and adolescents is virtually the same as that for adults, i.e., they are mainly indicated for the treatment of bipolar mood disorder. On the other hand, symptoms such as lack of impulse control and aggressiveness, seen in various other disorders, can also be controlled with drugs such as lithium, carbamazepine and valproic acid. These drugs may be used to treat this disorder, with no statistically significant difference as to their effects. Nevertheless, the literature reports many cases in which more than one mood stabilizer is necessary to control cycling mood disorder and manic episodes.

Precautions with the use of mood stabilizers in children and adolescents should be the same as in adults, including serum level monitoring of the drugs used and platelet count for the control of possible carbamazepine-induced leukopenia. Excessive weight gain may result from the use of valproic acid, and so may gastrointestinal distress at the beginning of treatment. The use of lithium in children requires careful maintenance of therapeutic levels, avoiding toxic levels, as liver metabolism is increased in this age group and there are greater risks of dehydration, especially among hyperactive individuals.

Lithium: doses vary and are defined according to body weight; lithium levels should range from 0.6 to $1.2 \mathrm{mEq} / \mathrm{l}$ (Table 1). The major side effects include nausea, vomiting, weight gain, headache, and tremors. Serum levels need to be carefully monitored to avoid toxicity, and one should be attentive to the occurrence of hypothyroidism and leukocytosis. ${ }^{3}$

Table 1 - Lithium doses for children and adolescents

\begin{tabular}{lc}
\hline Body weight & Dose \\
\hline Up to $25 \mathrm{~kg}$ & $600 \mathrm{mg} / \mathrm{day}$ \\
$25-40 \mathrm{~kg}$ & $900 \mathrm{mg} / \mathrm{day}$ \\
$40-50 \mathrm{~kg}$ & $1,200 \mathrm{mg} / \mathrm{day}$ \\
$50-60 \mathrm{~kg}$ & $1,500 \mathrm{mg} / \mathrm{day}$ \\
\hline
\end{tabular}

Carbamazepine: usual pediatric dose ranges from 200 to $600 \mathrm{mg} /$ day (20-60 mg/kg/day), but it may be increased, provided that serum levels ( 8 to $12 \mathrm{mg} / \mathrm{l}$ ) are controlled. The side effects of carbamazepine include leukopenia and maculopapular rash with edema. Dizziness, diplopia and nausea may occur at the beginning of treatment.

Valproic acid: doses range from 15 to $60 \mathrm{mg} / \mathrm{kg} / \mathrm{day}$, its half-life varies from 6 to 16 hours, and its serum levels should be 50 to $100 \mathrm{mg} / \mathrm{l}$. It may cause sedation and upset the gastrointestinal tract, but these effects are minimized with the use of divalproex sodium. Other side effects include weight gain and hepatotoxicity. Polycystic ovarian syndrome may be observed in girls.

According to the literature, the combination of lithium and divalproex sodium seems to be more efficacious in treating bipolar disorder in this age group, since only $50 \%$ of the patients respond to monotherapy during the acute phase. 4,5 
Mood disorder - depressive episode (ICD-10 F32)/major depressive disorder (DSM IV 296.2)

Selective serotonin reuptake inhibitors (SSRI) are currently the most widely used antidepressants in this age group, and this is related to safer side effects, with lower cardiotoxicity and lower risk of death from overdose. Another reason for the use of SSRI in children is that there is only one double-blind study, conducted in 1987, demonstrating the advantages of tricyclics over placebo. ${ }^{6}$ Some of the hypotheses about the paucity of data about tricyclics are: methodological failures such as low doses of antidepressant drugs, insufficient duration of treatment and small sample size. SSRI also were approved for use in the management of panic disorders and anxiety disorders. ${ }^{3}$

Fluoxetine chlorhydrate: initial pediatric doses range from 5 to $10 \mathrm{mg}$. The liquid formula is preferable, since it allows a better dose titration. The therapeutic dose ranges from 10 to $20 \mathrm{mg}$, and should be given in the morning to prevent insomnia. In adolescents, an initial morning dose of $10 \mathrm{mg}$ is used, and then increased to $20 \mathrm{mg}$ within one or two weeks. Doses for the treatment of obsessivecompulsive disorder in adolescents may be increased up to $80 \mathrm{mg}$, given twice a day, if no treatment response is obtained after five weeks. The doses recommended for bulimia are $60 \mathrm{mg}$ a day.

The major side effects include lack of appetite, weight loss, nausea, increased anxiety, insomnia and agitation. Fluoxetine is metabolized by cytochrome P450 2D6 enzyme system, and therefore, possible interactions with other drugs may occur, which could cause an increase in the serum levels of tricyclic antidepressants, carbamazepine, diazepam, and phenytoin, among others.

Sertraline chlorhydrate: initial doses consist of $25 \mathrm{mg}$ in the morning or at night with a $25-\mathrm{mg}$ increment every week, depending on clinical response. Therapeutic doses reported in the literature range from 25 to $200 \mathrm{mg}$ a day. These doses are recommended for the treatment of obsessive-compulsive disorder (OCD), panic disorder and posttraumatic stress disorder. In adults, the doses recommended for OCD are higher than those recommended for other disorders. The most common side effects include nausea, insomnia, diarrhea, drowsiness, and ejaculation disorders.

Paroxetine chlorhydrate: an initial dose of $20 \mathrm{mg}$ in the morning, which seems to be the therapeutic dose in most cases of depression and social phobia, is recommended. Therapeutic doses for the treatment of OCD and panic disorder are around $40 \mathrm{mg}$.

Side effects include fatigue, increased sweating, nausea, lack of appetite, drowsiness, dry mouth, dizziness, tremor, increased anxiety, sexual dysfunction, and insomnia. Paroxetine seems to have more noradrenergic effects than other SSRI.

SSRI may reduce the seizure threshold and provoke loss of libido. 7,8
Tricyclic antidepressants were widely used to treat children and adolescents for several years. Numerous open-label studies with imipramine, the best-known drug in this class, proved that it is efficient in the treatment of major depression in children, but no double-blind study has confirmed these findings. Studies with adolescents also revealed a poor treatment response. Other indications for the use of tricyclics are enuresis, attention deficit hyperactivity disorder and separation anxiety. Initial doses suggested for the treatment of major depressive disorder consist of $25 \mathrm{mg}$ at night, with a 25-mg increment every three days, depending on clinical response or until the maximum dose of $5 \mathrm{mg} / \mathrm{kg} /$ day is reached. This medication should be preferably given at night due to its sedative effect. Therapeutic response may be delayed and the medication should not be replaced before six weeks of treatment, when an adequate serum level between 125 and $250 \mathrm{mg} / \mathrm{ml}$ is obtained. The serum level of tricyclics varies considerably. Nortriptyline is the only tricyclic agent with a therapeutic window, with a serum level between 50 and $180 \mathrm{mg} / \mathrm{ml}$. The most frequent adverse effects are sedation, constipation, blurred vision, orthostatic hypotension, tachycardia, urinary retention, excitation, irritability, lack of appetite, increased sweating, and increased appetite. These drugs may reduce the seizure threshold and may cause cardiac conduction disease in doses higher than $3 \mathrm{mg}$ per $\mathrm{kg}$. In this case, a control ECG is recommended.

Clomipramine is indicated for the treatment of obsessive-compulsive disorder in initial doses of $25 \mathrm{mg} / \mathrm{kg}$ with a weekly dose escalation, depending on clinical response, up to a maximum dose of $3 \mathrm{mg} / \mathrm{kg}$. The maximum dose in adolescents is $250 \mathrm{mg}$ a day. The major risk of this drug is that it cumulatively reduces the seizure threshold. 3,7,9

Monoamine oxidase inhibitors (MAOI) are antidepressants that are rarely used in children and adolescents since they require a tyramine-free diet. MAOI have severe adverse effects and drug interactions, and may cause hypertension and seizures. Among the foods and drugs that must be avoided are cheese, chocolate, smoked foods, raisins, cold and asthma medications, stimulants, caffeine, tricyclics, etc. Some authors have shown good results with MAOI in the treatment of depression in adolescents who did not respond to tricyclics. ${ }^{3}$

Antidepressant therapy in cases of depression should last at least six months, and the same dose given in the acute phase should be maintained throughout this period. If a maintenance dose is not necessary, the medication should be discontinued within six weeks or more. Patients who could benefit from maintenance doses are those with multiple or severe episodes and patients at higher risk of relapse or with family history of recurrent depression or bipolar depression; patients with comorbidities; those under stressful or poorly supportive environmental situations; and patients with residual or subthreshold symptoms. 7,9 
Psychotic disorders - ICD-10: schizophrenia, schizotypical and delusional disorders F20 - F29, DSM IV: schizophrenia 295

In clinical practice, antipsychotic drugs are used to treat psychotic disorders and a wide variety of nonpsychotic conditions, including autism, Tourette's syndrome, mental retardation associated with behavioral disorders, and anger outbursts in children and adolescents with conduct disorder.

Antipsychotic drugs are of inestimable value for the psychiatric treatment of children and adolescents, but their use is restricted, due to the risk of tardive dyskinesia and withdrawal dyskinesia, and in some patients, weight gain and excessive sedation. This risk of tardive dyskinesia is minimized with the use of atypical antipsychotics.

Antipsychotics also are used to control frank psychotic symptoms, including delirium and/or hallucinations, helping patients to stay in touch with reality. There is however a wide variety of nonpsychotic diagnoses, in which antipsychotics are not aimed at treating the disease per se, but the target symptoms, such as stereotypies, aggressive behavior towards oneself or towards others, mannerisms, anger outbursts and hyperactivity symptoms that are responsive to both typical and atypical antipsychotics.

The side effects seen in children and adolescents are similar to those observed in adults. The most common extrapyramidal effects include dystonias, parkinsonism and sedation, especially with typical and powerful antipsychotics such as haloperidol. These effects are less common with atypical antipsychotics such as clozapine and risperidone.

Among the antipsychotic drugs most widely used to treat children and adolescents we have:

Haloperidol: drug in the class of butyrophenones, whose pediatric doses consist of 0.25 to $6 \mathrm{mg}(0.016$ $0.15 \mathrm{mg} / \mathrm{kg}$ ). Higher doses are recommended for acute psychotic symptoms, with monitoring of extrapyramidal effects.

Chlorpromazine: drug in the class of aliphatic phenothiazines, whose doses range from 10 to $200 \mathrm{mg}$ $(0.5$ to $3 \mathrm{mg} / \mathrm{kg})$. Side effects include sedation and skin photosensitization.

Thioridazine: a phenothiazine that can be used in doses of 10 to $200 \mathrm{mg}(0.5-3 \mathrm{mg} / \mathrm{kg})$. Adverse effects include sedation, dizziness, and enuresis.

Risperidone: atypical antipsychotic used in doses of 2 to $6 \mathrm{mg} /$ day. Side effects include sedation and weight gain. Extrapyramidal reactions are seldom observed.

\section{Anxiety disorders: ICD-F41-F43, DSM IV 300}

Although anxiety disorders are quite prevalent among children and adolescents, studies on the psychopharmacological treatment of these disorders are scarce. In general, small samples are used and response to placebo is high. The commonly used medications include antidepressants, SSRI and tricyclics, as previously mentioned. Other alternatives are beta-blockers and buspirone.

Benzodiazepines have a myorelaxant, anticonvulsant, hypnotic and anxiolytic action, and although their use in adults has been widely studied, there is a paucity of controlled studies about their effects on children and adolescents.

The efficacy of drugs such as alprazolam and clonazepam can be clearly confirmed in the treatment of somatic symptoms and autonomic signs of anxiety (palpitations, tremors, sweating) observed in different anxiety disorders (e.g.: panic disorder). Benzodiazepines can also control anxiety caused by specific circumscribed situations that children or adolescents might have to cope with, known as "anticipatory anxiety", related to episodes that could potentiate fear and anxiety (e.g.: medical procedures).

Double-blind studies show that alprazolam may be useful in children with generalized anxiety disorder and avoidance behavior in children and adolescents. Other studies show that clonazepam yields therapeutic results in children with separation anxiety disorder and in adolescents who suffer from panic disorder.

Dizziness and sedation are the most common side effects observed in children, being dose-dependent and self-limited, as tolerance develops. Other possible side effects include incoordination, diplopia, tremors and behavioral disinhibition or paradoxical effect, common in especially very young children, and which is characterized by irritability, anger outbursts and lack of impulse control.

The power that these drugs have to develop tolerance or dependency is widely known, therefore, they should be used for short periods of time, and gradually withdrawn, so that abstinence symptoms or rebound anxiety can be avoided. 10,11

Hyperkinetic disorders - disturbance of activity and attention $F$ 90.0, attention deficit hyperactivity disorder DSM IV 314

Stimulants are the drugs of choice to treat these disorders, with favorable response in $75 \%$ of cases. Methylphenidate is the most frequently used stimulant in Brazil. It is widely studied, with several double-blind studies showing that it is superior to placebo. Some studies show that stimulants outperform the efficacy of tricyclics, especially regarding inattention. The latter ones are used as first-line drugs by some physicians in cases of comorbid diagnoses, such as depressive disorders or anxiety disorders.

Methylphenidate has a rapid onset and improves symptoms within the first hours after administration. Peak serum levels occur within one or two and a half hours after administration, and serum half-life is of approximately two and a half hours. The symptoms that respond to this 
medication include inattention, hyperactivity, impulsivity and aggressiveness.

Therapeutic doses range from 0.3 to $0.7 \mathrm{mg} / \mathrm{kg}$. Initial treatment consists of $10 \mathrm{mg}$ given once or twice a day, with weekly dose escalation, depending on clinical response and side effects. Maximum daily dose is $60 \mathrm{mg}$. Symptoms improve 20 minutes after administration, and the therapeutic effect lasts for 4 to 6 hours. Among the most frequently reported adverse effects are loss of appetite, insomnia, gastrointestinal distress, increase of heart rate and arterial blood pressure, mood swings, headache, and growth arrest. The latter symptom can be reversed by medication-free periods (e.g.: vacations), which allows growth to be restored. Stimulants may cause tics in children with personal or family history of tics. Psychotic symptoms may occur, so its use is contraindicated in children with severe borderline personality disorder, schizophrenia, and other psychotic disorders. ${ }^{3,11}$

Tricyclic antidepressants, especially imipramine, are often used to treat ADHD. Other medications, still unavailable in Brazil, include atomoxetine (powerful selective norepinephrine reuptake inhibitor), Adderal XR (mixed amphetamine salts), OROS MPH (osmotic release oral system for methylphenidate) and modafinil (wakefulness-promoting agent that activates the cerebral cortex). ${ }^{12}$

Global developmental delay - pervasive developmental disorders - F 84

Pervasive developmental disorders include autistic disorder, Asperger's syndrome, Rett's syndrome, childhood disintegrative disorder, and global developmental delay (GDD) not otherwise specified.

The target symptoms for the treatment of these disorders include motor hyperactivity, inattention, repetitive behaviors and tics, self-mutilation and selfdestructiveness, and impaired social interactions.

The use of stimulants or alpha-2-adrenergic agonists is recommended for motor hyperactivity and inattention.

Preliminary studies with dextroamphetamine and levoamphetamine yielded frustrating results. More recent and smaller controlled studies with methylphenidate showed improvement in hyperactivity and irritability. Side effects include insomnia, anorexia, irritability and aggressiveness. A controlled study with methylphenidate is currently being conducted by the Research Units on Pediatric Psychopharmacology (RUPP) Autism Network. ${ }^{13}$

Clonidine (alpha-2-adrenergic agonist) seems to yield inconsistent results, with improvement of hyperactivity, irritability, stereotypies, inappropriate speech and oppositional behavior. Adverse effects include hypotension, sedation and irritability.

Guanfacine (alpha-2-adrenergic agonist) has some advantages over clonidine, its half-life is longer, allowing for less frequent doses and less rebound hypertension; it seems to be less sedative and causes less hypotension than clonidine. ${ }^{3}$

The use of selective serotonin reuptake inhibitors (SSRI) is indicated for repetitive behavior and motor and/ or vocal tics.

Clomipramine (152 mg/day or $4.3 \mathrm{mg} / \mathrm{kg} /$ day) in a double-blind (crossover) study with 28 individuals (6-23 years old) diagnosed with autism proved more efficient in treating symptoms of autism, irritability, oppositional symptoms and obsessive-compulsive symptoms than desipramine (127 mg/day: $4.0 \mathrm{mg} / \mathrm{kg} /$ day). Both drugs showed comparable results with regard to hyperactivity. The side effects of clomipramine include tachycardia, decrease in the seizure threshold and prolongation of the QT interval on ECG.

Fluvoxamine in a double-blind study (parallel groups) was compared with placebo in 30 autistic adults for 12 weeks. The results showed that eight of 15 fluvoxaminetreated patients versus none of 15 placebo-treated patients had a therapeutic response to the following symptoms: repetitive thoughts and behaviors, aggressiveness, and some aspects of social interaction (especially speech). Adverse effects included mild sedation and nausea. ${ }^{14}$ In a double-blind study (parallel groups) with children and adolescents (5-18 years old), in which fluvoxamine was used for twelve weeks in an average dose of $115.6 \mathrm{mg} /$ day, the authors observed control of symptoms in 1 of 18 fluvoxamine-treated patients and in 0 of 16 placebotreated patients. Adverse effects included aggressiveness, agitation, anxiety, anorexia, insomnia and motor hyperactivity (Mc Dougle C, published data, Annual Meeting 2003, American Psychiatric Association).

Other drugs used to control these symptoms are fluoxetine, sertraline, paroxetine and citalopram.

Antipsychotics are indicated to treat aggressiveness, self-mutilation, and destructiveness.

The use of haloperidol in the treatment of autism has been widely studied, showing improvement of withdrawal, stereotypies, hyperactivity, emotional instability, negativism and anger. The major side effects include chronic and acute dyskinesias.

Atypical antipsychotic drugs include clozapine, risperidone, olanzapine, quetiapine and ziprasidone (commercially unavailable in Brazil).

Studies with clozapine are scarce; there have been only some case reports. In this case, complicating factors include agranulocytosis, which requires regular blood tests and decreases the seizure threshold.

Numerous clinical studies have been carried out with risperidone. In a double-blind study that compared risperidone with placebo in 31 patients (aged between 18 and 43 years), of whom 17 were autistic and 14 had pervasive developmental disorder with no other specification, risperidone $(2.9 \pm 1.4 \mathrm{mg} / \mathrm{d})$ was more efficacious than placebo ( $8 / 14$ patients versus $0 / 16$ patients) in treating the following symptoms: 
aggressiveness, anxiety/nervousness, depression, irritability and autistic behaviors. Mild sedation was the most frequently observed side effect. The second study conducted by the Research Units on Pediatric Psychopharmacology - Autism Network revealed that risperidone was superior to placebo. Side effects included weight gain, fatigue, drowsiness, dizziness, and increased salivation. 15

Olanzapine was assessed in small open-label studies and in case reports, and the results showed that it was more efficacious than haloperidol, causing fewer extrapyramidal effects, but more weight gain. Controlled studies should be conducted. ${ }^{3}$

Few studies have been available on quetiapine; there is only a small open-label study and some case reports. ${ }^{3}$

With regard to ziprasidone, there is a retrospective case series study with 12 individuals (mean age $11.62 \pm 4.38 ; 8$ to 20 years), who received an average dose of $59.23 \pm 34.76 \mathrm{mg} /$ day; $20-120 \mathrm{mg} /$ day. Results showed that six out of 12 patients had a therapeutic response in the Clinical Global Impression Scale (CGI) and that significant weight gain was not observed. ${ }^{16}$

Impaired social interaction should be treated with glutaminergic agents, as they seem to be more efficient in controlling the negative symptoms of schizophrenia. Glutaminergic agents include lamotrigine, amantadine and D-cycloserine.

Other drugs used to treat these cases are mirtazapine (useful in treating anxieties related to separation and transitions); valproic acid, and aripiprazole.

There has been substantial development in the treatment of pervasive developmental disorders, including autism. The pharmacological treatment of these diseases is aimed at the target symptoms. Several younger patients present with hyperactivity and inattention. So far, studies on the use of psychostimulants to treat these symptoms have yielded negligible results. Preliminary studies with alpha-2-adrenergic agonists have shown promising results. Large-scale studies about these agents have been under way. Ritualistic behaviors are symptoms that often require drug therapy. A small number of controlled studies with selective serotonin reuptake inhibitors (SSRI) suggest that these drugs may help resolve these symptoms, especially in postpubertal patients. Aggressiveness, self-mutilation and destructive behavior may occur. Atypical antipsychotic drugs may be efficient in treating these symptoms. The NIMH-sponsored Research Units on Pediatric Psychopharmacology (RUPP) Network has recently concluded a controlled study with risperidone with 101 autistic children and adolescents, which demonstrated a significant improvement of aggressive symptoms. ${ }^{13}$ Studies with drugs whose target symptoms are the impaired social interactions in autism and other global developmental delays, including agents with predominant effect on the glutamatergic system, have shown promising results. ${ }^{3}$

\section{Final remarks}

Psychopharmacology regarding the treatment of children and adolescents has many unanswered questions, despite the advances made throughout the last decades. An example of this is that the parameters used to decide on length of treatment, maintenance dose, etc, are still dependent upon the parameters used for adult patients.

In spite of these limitations, psychotic drugs, if properly prescribed, may substantially contribute to the development of pediatric patients.

\section{Antiepileptic drugs (AEDs)}

Epilepsy affects 0.5 to $1 \%$ of pediatric patients, in whom most seizures occur during the first years of life. Before implementing a treatment with antiepileptic drugs (AED), the greatest challenge consists in defining the type of seizure, establishing the syndromic diagnosis of epilepsy, and guiding patients and their families. The total control of seizures without adverse effects may be obtained in many patients, but this is still far from being a routine practice in the treatment of childhood epilepsy. With typical therapeutic drugs, at least $25 \%$ of epileptic children remain refractory to treatment. When the treatment with typical drugs fails, new AEDs have to be used. Therapeutic failure concerning AEDs may constitute an incomplete control of seizures without adverse effects; a complete control of seizures only possible with adverse effects; or an incomplete control of seizures with persistent adverse effects. ${ }^{17}$

\section{Pharmacokinetics in children and adolescents}

Pharmacology plays a crucial role in the selection of antiepileptic drugs. Bioavailability, metabolism, excretion, pharmacokinetics and drug interactions should be considered. ${ }^{18}$

In children, it is difficult to customize the dose of AEDs; in adults, higher doses per body weight are necessary; except for the neonatal period, the short elimination halflife requires more frequent administrations so that serum levels remain stable; and, finally, monitoring of serum levels is more important in this age group. ${ }^{19}$

\section{Basic principles}

Drug therapy is indicated to treat epilepsy when there is increased likelihood of seizure recurrence and, usually, after the second unprovoked seizure (excluding febrile seizures). For most patients, the use of a single AED (monotherapy) results in higher treatment compliance, wider therapeutic window, and is more efficient than polytherapy, in addition to producing fewer adverse effects. ${ }^{19}$ The rational therapeutic approach consists in selecting the medication according to patient's characteristics, taking into account the type of seizure, epilepsy syndrome, individual peculiarities, physician's experience, availability or cost of medication. ${ }^{17}$ 
The selection of AEDs varies with the type of seizure and/or epilepsy syndrome (Table 2). Adverse effects restrict the selection of AEDs, as well as the drug interactions between AEDs (in polytherapy) or other drugs (Tables 3 and 4).20,21

Antiepileptic therapy may be discontinued when patients are free from seizures, simple partial seizures or generalized seizures for 2 to 5 years; or when neurological exams, and IQ are normal, and when EEG findings have returned to normal after treatment. ${ }^{22}$

\section{Major childhood epilepsy syndromes West syndrome - ICD-10: G40.0}

West syndrome is an age-dependent epileptic encephalopathy characterized by a triad of infantile spasms, mental retardation or regression, and an interictal EEG pattern termed hypsarrhythmia. Prognosis often is unfavorable. 23

First-line treatment consists of corticosteroid therapy (single-dose prednisone $2 \mathrm{mg} / \mathrm{kg} /$ day, for two weeks with gradual withdrawal for three more weeks), natural ACTH ( $75 \mathrm{IU} / \mathrm{m}^{2}$ IM twice a day for 2 weeks, with gradual withdrawal for two more weeks) or synthetic ACTH (1020 IU given intramuscularly once a day for 2 weeks, with gradual withdrawal for six more weeks). Precautions should be taken regarding arterial blood pressure measurements, tests for glycosuria, electrolytes and blood sugar levels. 23,24

Vigabatrin is particularly efficient in treating infantile spasms associated with tuberous sclerosis, and is used in the dose of 20 to $400 \mathrm{mg} / \mathrm{kg} / \mathrm{day}$, depending on the literature used. Most side effects of vigabatrin are transient and well tolerated, except for the risk of irreversible visual field defects in up to $40-50 \%$ of cases. 25,26

The use of topiramate as an adjuvant drug in the dose of 2 to $24 \mathrm{mg} / \mathrm{kg} /$ day has yielded promising results. 27 Zonisamide (unavailable in Brazil) has been used in the dose of 4 to $8 \mathrm{mg} / \mathrm{kg} /$ day, divided into two doses, and has controlled seizures in 20 to $38 \%$ of cases. It may be used as monotherapy or as an adjuvant drug. 28

High-dose vitamin B6 controls seizures in 10 to $30 \%$ of cases. Gastrointestinal symptoms occur in up to $70 \%$ of cases. ${ }^{29}$ Thyrotropin-releasing hormone $-0.05 \mathrm{mg} /$ $\mathrm{kg}$ IV in the first week, followed by the same IM dose for two more weeks, discontinued for two weeks, and resumed with $0.05 \mathrm{mg} / \mathrm{kg}$ IM for two more weeks - has proven efficacious and safe. ${ }^{30}$

\section{Lennox-Gastaut syndrome - ICD-10: G40.4}

It is an age-specific syndrome characterized by tonicaxial seizures, atypical absence seizures, and sudden falls caused by atonic and myoclonic seizures. A characteristic EEG pattern is observed, and there is a delay in neuropsychomotor development associated or not with psychiatric disorders. 31

Few patients are able to control seizures with monotherapy, since total control of seizures is obtained in only $5 \%$ of patients, even with polytherapy. The most usual alternative is to combine sodium valproate (up to $60 \mathrm{mg} / \mathrm{kg} /$ day divided into two or three doses) with one of the following drugs: clobazam (10 to $40 \mathrm{mg} /$ day in two daily doses), clonazepam ( 0.1 to $0.3 \mathrm{mg} / \mathrm{kg} / \mathrm{day}$ ), nitrazepam ( $1 \mathrm{mg} / \mathrm{kg} /$ day), vigabatrin (initial dose of 50 to $80 \mathrm{mg} / \mathrm{kg} /$ day with an increment of up to $150 \mathrm{mg} / \mathrm{kg} /$ day) or lamotrigine ( $2 \mathrm{mg} / \mathrm{kg} /$ day up to $7 \mathrm{mg} / \mathrm{kg} /$ day, or up to three times lower if combined with valproic acid).

Table 2 - First and second-choice AEDs according to the type of seizure

\begin{tabular}{|c|c|c|c|c|c|}
\hline & \multirow[t]{2}{*}{ Partial seizures } & \multicolumn{4}{|c|}{ Generalized seizures } \\
\hline & & Tonic-clonic & Absence & Myoclonic & Atonic/Clonic \\
\hline $\begin{array}{l}\text { Fisrt-choice } \\
\text { drugs }\end{array}$ & $\begin{array}{l}\text { Carbamazepine } \\
\text { Phenytoin }\end{array}$ & $\begin{array}{c}\text { Carbamazepine } \\
\text { Phenytoin } \\
\text { Valproate }\end{array}$ & $\begin{array}{l}\text { Ethosuximide } \\
\text { Valproate }\end{array}$ & $\begin{array}{l}\text { Valproate } \\
\text { Clonazepam }\end{array}$ & Valproate \\
\hline $\begin{array}{l}\text { Second-choice } \\
\text { drugs }\end{array}$ & $\begin{array}{l}\text { Valproate } \\
\text { Phenobarbital } \\
\text { Topiramate } \\
\text { Lamotrigine } \\
\text { Vigabatrin } \\
\text { Gabapentin }\end{array}$ & $\begin{array}{c}\text { Phenobarbital } \\
\text { Lamotrigine } \\
\text { Topiramate }\end{array}$ & $\begin{array}{l}\text { Clonazepam } \\
\text { Lamotrigine } \\
\text { Topiramate }\end{array}$ & $\begin{array}{c}\text { Phenobarbital } \\
\text { Lamotrigine } \\
\text { Topiramate }\end{array}$ & $\begin{array}{l}\text { Clonazepam } \\
\text { Nitrazepam } \\
\text { Topiramate } \\
\text { Lamotrigine }\end{array}$ \\
\hline
\end{tabular}

Modified from Yacubian ${ }^{19}$. 
Table 3 - Main systemic and neurotoxic effects and rare adverse reactions to the AEDs

\begin{tabular}{|c|c|c|}
\hline AED & Systemic and neurotoxic effects & Rare adverse reactions \\
\hline Carbamazepine & $\begin{array}{l}\text { Nausea, vomiting, diarrhea, hyponatremia, } \\
\text { rash, itching, urine retention, sleepness, } \\
\text { headache, blured vision, diplopia, dizziness. }\end{array}$ & $\begin{array}{l}\text { Agranulocitosis, Stevens-Johnson syndrome, } \\
\text { aplasic anemia, renal insufficiency, } \\
\text { dermatitis/rash, serum disease, pancreatitis. }\end{array}$ \\
\hline $\begin{array}{l}\text { Phenobarbital/ } \\
\text { primidone }\end{array}$ & $\begin{array}{c}\text { Nausea, rash, insomnia, sedation, } \\
\text { bahavioral alteration, hyperactivity, } \\
\text { ataxia, tolerance, dependence. }\end{array}$ & $\begin{array}{c}\text { Agranulocitosis, Stevens-Johnson syndrome, } \\
\text { aplasic anemia, renal insufficiency, } \\
\text { dermatitis/rash, serum disease. }\end{array}$ \\
\hline Phenytoin & $\begin{array}{l}\text { Gum hypertrophy, hirsutism, rash, } \\
\text { lymphadenopathy, ataxia, confusion, } \\
\text { diplopia, neuropathy. }\end{array}$ & $\begin{array}{c}\text { Agranulocitosis, Stevens-Johnson syndrome, } \\
\text { aplasic anemia, renal insufficiency, } \\
\text { dermatitis/rash, serum disease. }\end{array}$ \\
\hline Valproate & $\begin{array}{l}\text { Weight gain, nausea, vomiting, } \\
\text { hair loss, trembling. }\end{array}$ & $\begin{array}{c}\text { Agranulocitosis, Stevens-Johnson syndrome, } \\
\text { aplasic anemia, renal insufficiency, } \\
\text { dermatitis/rash, serum disease. }\end{array}$ \\
\hline Ethosuximide & $\begin{array}{l}\text { Nausea, vomiting, sleep disorder, } \\
\text { hyperactivity }\end{array}$ & $\begin{array}{l}\text { Agranulocitosis, Stevens-Johnson syndrome, } \\
\text { aplasic anemia, dermatitis/rash, serum disease. }\end{array}$ \\
\hline Felbamate & $\begin{array}{l}\text { Nausea, vomiting, anorexia, } \\
\text { weight loss, dizziness. }\end{array}$ & $\begin{array}{l}\text { Aplasic anemia, } \\
\text { renal insufficiency. }\end{array}$ \\
\hline Gabapentin & $\begin{array}{l}\text { Sleepness, ataxia, headache, dizziness, } \\
\text { nystagmus, abnormal coordination, } \\
\text { mood disorder and thought disorder. }\end{array}$ & \\
\hline Lamotrigine & Sleepness, nausea, dizziness, diplopia. & Stevens-Johnson syndrome, dermatitis/rash. \\
\hline Topiramate & $\begin{array}{c}\text { Sleepness, fatigue, dizziness, weight loss, } \\
\text { nystagmus, diplopia, renal calculus, } \\
\text { bahavioral disorder. }\end{array}$ & \\
\hline Tiagabine & $\begin{array}{l}\text { Sleepness, fatigue, dizziness, weight loss, } \\
\text { nystagmus, diplopia, behavioral disorder. }\end{array}$ & \\
\hline Vigabatrin & $\begin{array}{l}\text { Sleepness, fatigue, dizziness, weight gain, } \\
\text { nystagmus, diplopia, bahavioral disorder, } \\
\text { visual alterations. }\end{array}$ & \\
\hline Oxcarbazepine & Giddiness, alergy, fatigue, dizziness. & \\
\hline
\end{tabular}

Modified from Holmes ${ }^{20}$.

Topiramate may be used to control tonic and atonic seizures. Corticosteroids are reserved for cases of nonconvulsive status epilepticus or with exacerbation of seizure frequency. Some children may benefit from a ketogenic diet. 31

\section{Benign myoclonic epilepsy in infancy- ICD: G40.3}

It is idiopathic, with short myoclonic seizures and with variable generalized seizures. It affects children younger than three years and with family history of epilepsy. It offers a good prognosis, but it may develop into generalized tonic-clonic seizures in adolescence. Valproate totally controls the seizures; if left untreated, seizures may persist for several years. Hepatotoxicity should be considered a possible adverse effect. 32

\section{Panayiotopoulos-type benign childhood occipital epilepsy - ICD 10: G 40.0}

Seizures may be characterized by visual hallucinations, symptoms of visual field defects, visual 
Table 4 - Main drug interactions between AEDs

\begin{tabular}{|c|c|c|c|c|c|c|c|c|}
\hline \multicolumn{9}{|c|}{ Conventional AEDs effects on the new drugs } \\
\hline Drugs & Gabapentine & \multicolumn{2}{|c|}{ Lamotrigine } & \multicolumn{2}{|c|}{ Topiramate } & \multicolumn{2}{|c|}{ Oxcarbamazepine } & Vigabatrine \\
\hline Phenytoin & None & \multicolumn{2}{|c|}{$\begin{array}{c}\text { Reduced } \\
\text { serum level }\end{array}$} & \multicolumn{2}{|c|}{$\begin{array}{c}\text { Reduced } \\
\text { serum level }\end{array}$} & \multicolumn{2}{|c|}{$\begin{array}{c}\text { Reduced } \\
\text { serum level }\end{array}$} & None \\
\hline Carbamazepine & None & \multicolumn{2}{|c|}{$\begin{array}{c}\text { Reduced } \\
\text { serum level }\end{array}$} & \multicolumn{2}{|c|}{$\begin{array}{c}\text { Reduced } \\
\text { serum level }\end{array}$} & \multicolumn{2}{|c|}{$\begin{array}{c}\text { Reduced } \\
\text { serum level }\end{array}$} & None \\
\hline Valproate & None & \multirow{2}{*}{\multicolumn{2}{|c|}{$\begin{array}{l}\text { Increased } \\
\text { serum level } \\
\text { Reduced } \\
\text { serum level }\end{array}$}} & \multirow{2}{*}{\multicolumn{2}{|c|}{$\begin{array}{l}\text { None } \\
\text { Reduced } \\
\text { serum level }\end{array}$}} & \multirow{2}{*}{\multicolumn{2}{|c|}{$\begin{array}{c}\text { None } \\
\text { Reduced } \\
\text { serum level }\end{array}$}} & None \\
\hline Phenobarbital & None & & & & & & & None \\
\hline \multicolumn{9}{|c|}{ AEDs effect on conventional drugs } \\
\hline Drugs & \multicolumn{2}{|c|}{ Phenytoin } & \multicolumn{2}{|c|}{ Carbamazepine } & \multicolumn{2}{|c|}{ Valproate } & \multicolumn{2}{|c|}{ Phenobarbitall } \\
\hline Gabapentine & \multicolumn{2}{|l|}{ None } & \multicolumn{2}{|c|}{ None } & \multicolumn{2}{|r|}{ None } & \multicolumn{2}{|r|}{ None } \\
\hline Lamotrigine & \multicolumn{2}{|l|}{ None } & \multicolumn{2}{|c|}{ None } & \multicolumn{2}{|c|}{$\begin{array}{l}\text { Reduction of } 25 \% \\
\text { in the serum level }\end{array}$} & & None \\
\hline Topiramate & \multicolumn{2}{|c|}{$\begin{array}{c}\text { Serum level } \\
\text { might be increased }\end{array}$} & \multicolumn{2}{|c|}{ None } & \multicolumn{2}{|r|}{ None } & & None \\
\hline Oxcarbamazepine & \multirow{2}{*}{\multicolumn{2}{|c|}{$\begin{array}{c}\text { Serum level } \\
\text { might be increased } \\
\text { Reduction in the } \\
\text { serum level }( \pm 20 \%)\end{array}$}} & \multicolumn{2}{|c|}{ None } & \multicolumn{2}{|r|}{ None } & \multirow{2}{*}{\multicolumn{2}{|c|}{$\begin{array}{l}\text { Mild increase } \\
\text { in the serum level } \\
\text { None }\end{array}$}} \\
\hline Vigabatrine & & & & & & None & & \\
\hline
\end{tabular}

Modified from French \& Gidal. ${ }^{21}$

illusions, and loss of consciousness. Interictal EEG shows bilateral occipital spike-and-wave discharges at a frequency of 1.5 to $2.5 \mathrm{cps}$. Paroxysmal activities tend to subside or disappear when the patient opens his/her eyes. Good response often is obtained with carbamazepine, diphenylhydantoin or clobazam.33,34

\section{Benign childhood epilepsy with centrotemporal EEG spikes - ICD 10: G 40.0}

This is the most common type of childhood partial epilepsy. Seizures occur between the ages of 3 and 10 years, and boys are more often affected than girls. Neuropsychomotor development is normal. 35

The use of AEDs is not always necessary in benign rolandic epilepsies. In this case, most antiepileptic drugs are efficacious, and carbamazepine is one of the drugs of choice. 35

\section{Childhood absence epilepsy - ICD 10: G 40.3}

This is the most common type of absence seizures. It affects previously healthy children with family history of epilepsy in 15 to $30 \%$ of cases. Seizures consist of sudden loss of consciousness during 5 seconds to 1 minute. The EEG shows interictal and ictal paroxysms of generalized $3-\mathrm{Hz}$ spike-wave complexes. Seizures may be caused by hyperpnea, drowsiness, and certain cognitive activities. 33,34

Recommended treatment consists of sodium valproate (initial dose of $15 \mathrm{mg} / \mathrm{kg} /$ day up to a maximum dose of 60 $\mathrm{mg} / \mathrm{kg} /$ day) or ethosuximide (initial dose of 125 to 250 $\mathrm{mg} /$ day up to a maximum dose of $50 \mathrm{mg} / \mathrm{kg} / \mathrm{day}$ - this drug is not available in Brazil), in monotherapy, with approximately $80 \%$ of therapeutic success. If necessary, valproate and ethosuximide can be combined, or secondline treatment with lamotrigine, clonazepam and acetazolamide should be implemented. Carbamazepine can potentiate seizures and cause absence seizures. 33,34

\section{Juvenile absence epilepsy - ICD: G $\mathbf{4 0 . 3}$}

It may be a continuum of childhood absence epilepsy, but with onset around puberty and with a higher frequency of generalized tonic-clonic seizures. The treatment is the same as that for childhood absence seizures. ${ }^{34}$ 


\section{Juvenile myoclonic epilepsy- ICD 10: G 40.3}

It is an inherited disorder whose gene was mapped on chromosome 6. Besides myoclonic seizures, generalized tonic-clonic and absence seizures may also occur. Presents excellent response to valproic acid, but recurrence may occur after withdrawal of medication. 32

\section{Complex partial seizures - ICD 10: G 40.2}

These seizures often occur in the temporal cortex, but may also develop in the frontal or parietal cortex. Treatment options include carbamazepine, phenytoin, primidone or valproate. 36

Therapeutic indications, doses and mechanism of action of the most common AEDs are described next:

Carbamazepine: blocks sodium channels at the presynaptic and postsynaptic levels. ${ }^{36}$ It is efficient in controlling simple or complex partial seizures, and generalized tonic-clonic seizures. It may increase the frequency of generalized absence seizures. Low doses should be initially used, with dose escalation within 2 to 7 days. Maintenance dose is around $20 \mathrm{mg} / \mathrm{kg} /$ day. ${ }^{34}$

Phenytoin: stabilizes excitable cell membranes and reduces membrane sodium gradient, which results in a decrease in its intracellular levels. Also restricts the permeability of the membrane to calcium. ${ }^{36}$ It is a quite efficient drug, and there are no statistically significant differences between phenytoin and carbamazepine as to the prevention of partial and generalized tonic-clonic seizures. However, due to its adverse effects, it should be regarded as a second-line drug, especially in girls. Its pharmacokinetics may be unpredictable at times, due to its metabolism. In status epilepticus, it must be slowly infused into a large vein in the dose of $18 \mathrm{mg} / \mathrm{kg}$. Maintenance dose consists of 4 to $7 \mathrm{mg} / \mathrm{kg} /$ day. 19,34

Sodium valproate: sodium channel antagonist that affects the action of GABA (gamma aminobutyric acid). Used to control generalized tonic-clonic seizures, absence seizures, myoclonic seizures and mixed seizures; and to a lesser extent, focal seizures. Maintenance dose consists of 30 to $60 \mathrm{mg} / \mathrm{kg} /$ day. ${ }^{8}$ Divalproex sodium, which is more stable and more tolerable, has been made available recently. 34,37

Phenobarbital: drug with a selective sedative effect on the motor cortex. Increases the threshold of normal cells and presynaptic inhibition, thus reducing repetitive discharges of neurons in the epileptogenic focus. Also potentiates the inhibitory effects of GABA. ${ }^{36}$ Efficient in treating focal and generalized seizures and status epilepticus that is refractory to diphenylhydantoin and benzodiazepines, in the dose of $20 \mathrm{mg} / \mathrm{kg}$ IV. Also indicated for seizures in the neonatal period. Maintenance dose consists of 3 to $5 \mathrm{mg} / \mathrm{kg} /$ day twice a day in the first six months of life and once a day thereafter. Withdrawal must be slow and gradual in order to avoid the wellestablished risk of seizure exacerbation. 34,36
Vigabatrin: irreversible GABA-transaminase inhibitor. ${ }^{36}$ Especially indicated for infantile spasms and West syndrome (particularly for patients with tuberous sclerosis), but may used in severe generalized epilepsies, as in LennoxGastaut syndrome. Dose ranges from 40 to $200 \mathrm{mg} / \mathrm{kg} /$ day, given in one or two divided doses. 24

Lamotrigine: this drug stabilizes the neuronal membranes by blocking sodium channels and releasing glutamic acid, a CNS excitatory neurotransmitter. ${ }^{33}$ Efficient in treating focal seizures, but may be used in idiopathic generalized epilepsy, especially in juvenile myoclonic epilepsy, and in idiopathic generalized seizures and secondary generalized epilepsies, particularly in juvenile myoclonic epilepsy and in Lennox-Gastaut syndrome. 31 The recommended dose consists of 5 to $15 \mathrm{mg} / \mathrm{kg} /$ day, with an initial dose of $2 \mathrm{mg} / \mathrm{kg}$ twice a day. The dose can be reduced when combined with valproate. ${ }^{34}$

Oxcarbazepine: this drug blocks voltage-sensitive sodium, potassium and calcium channels. Efficiency is similar to that of carbamazepine, but its side effects are less strong due to the lack of metabolite10,11-epoxide (responsible for the toxicity). The fact that this drug does not use the microsomal $\mathrm{P}-450$ system prevents the induction of other antiepileptic drugs, and does not interfere with the metabolism of other endogenous drugs and substances. Used for partial epilepsies with or without generalized secondary seizures, in an average dose of 20 to $40 \mathrm{mg} / \mathrm{kg} /$ day. 34

Topiramate: this drug blocks sodium channels and potentiates GABA-mediated effects, acts a glutamate receptor antagonist, and inhibits carbonic anhydrase. 34,38 Among the most recent drugs, it is regarded as one of the most efficient in the treatment of patients who are refractory to first-line drugs. Efficient in treating focal seizures, Lennox-Gastaut syndrome, West syndrome, and juvenile myoclonic epilepsy. Maintenance dose consists of 3 to 6 $\mathrm{mg} / \mathrm{kg} /$ day, with an initial dose of $0.5 \mathrm{mg} / \mathrm{kg} /$ day. Dose may be escalated every two weeks. ${ }^{38}$

Gabapentin: the mechanism of action of this drug has not been unraveled yet; its effect may be related to the change in the concentration of amino acids in the nervous system. Indicated for focal seizures. Worsens myoclonic seizures. The dose ranges from 30 to $90 \mathrm{mg} / \mathrm{kg} / \mathrm{day} .39$

\section{Final remarks}

AEDs should be rationally used in children, and should be recommended only when indication is accurate. All AEDs have possible side effects that may be more relevant in individuals whose central nervous system is still developing. Decisions about the treatment must be based on the precise diagnosis of epilepsy and/or risk of seizure recurrence, and on the selection of drugs according to patients' individual characteristics. Seizure types, epilepsy syndrome, the use of adjuvant drugs, physician's experience with AEDs and their side effects, should all be 
considered. The availability of medication (from health services, in the Brazilian market, or from abroad) and its cost should also be considered. In our setting, noncompliance to antiepileptic therapy is highly dependent upon the cost of medications.

\section{References}

1. Green WH. Princípios da psicofarmacoterapia e tratamento com drogas específicas. In: Lewis, Melvin, editores. Tratado de psiquiatria da infância e adolescência. Batista D, Costa S, Ortiz I, tradutores. Porto Alegre, Artes Médicas; 1995.

2. Riddle MA. Farmacocinética nas crianças e nos adolescentes. In: Lewis, Melvin, editores. Tratado de psiquiatria da infância e adolescência. Batista D, Costa S, Ortiz I, tradutores. Porto Alegre, Artes Médicas; 1995.

3. Green WH. Child and Adolescent Clinical Psychopharmacology. 3rd ed. New York: Barnes \& Nobles; 2001.

4. Kowatch RA, Suppes T, Carmody TJ, Bucci JP, Hume JH, Kromelis M, et al. Effect size of lithium, divalproex sodium, and carbamazepine in children and adolescents with bipolar disorder. J Am Acad Child Adolesc Psychiatry. 2000;39:713-20.

5. Pavuluri MN, Naylor MW, Janicak PG. Recognition and treatment of pediatric bipolar disorder. Contemporary Psychiatry. $2000 ; 1(1)$.

6. Preskorn $\mathrm{SH}$, Weller EB, Hughes $\mathrm{CW}$, Weller RA, Bolte K. Depression in prepubertal children: dexamethasone nonsuppression predicts differential response to imipramine vs. Placebo. Psychopharmacol Bull. 1987;23(1):128-33.

7. Birmaher $B$, Brent $D$. Practice parameters for the assessment and treatment of children and adolescents with depressive disorders. J Am Acad Child Adolesc Psychiatry. 1998;37 Suppl:10.

8. Campbell M, Rapoport J, Simpson G. Practitioner's guide to psychoactive drugs for children and adolescents. J Am Acad Child Adolesc Psychiatry. 1999;38(5):537-43.

9. Hughes CW, Emslie GJ, Crismon ML, Wagner KD, Birmaher B, Geller B, et al. The Texas Children's Medication Algorithm Project: Report of the Texas Consensus Conference Panel on Medication Treatment of Childhood Major depressive Disorder. J Am Acad Child Adolesc Psychiatry. 1999;38(11):1442-54

10. Riddle MA, Bernstein GA, Cook EH, Leonard HL, March JS, Swanson JM. Anxiolytics, adrenergic agents, and naltrexone. J Am Acad Child Adolesc Psychiatry. 1999;38(5):546-54.

11. Rocha GP. Psicofarmacologia na Infância e Adolescência. In: Fichtner N. Prevenção, Diagnóstico e Tratamento dos Transtornos Mentais da Infância e da Adolescência: um enfoque desenvolvimental. Porto Alegre: Artes Médicas; 1997. p. 263-78.

12. AACAP Practice Parameters for the use of stimulant medications in the treatment of children, adolescents and adults. J Am Acad Child Adolesc Psychiatry. 2002;41 Suppl 2:26-49.

13. RUPP Autism Network. N Engl J Med. 2002;347:314-21.

14. McDougle CJ, Naylor ST, Cohen DJ, Volkmar FR, Heninger GR, Price LH. A double-blind, placebo-controlled study of fluvoxamine in adults with autistic disorder. Arch Gen Psychiatry. 1996;53:1001-8.

15. McDougle CJ, Holmes JP, Carlson DC, Pelton GH, Cohen DJ, Price $\mathrm{LH}$. A double-blind, placebo controlled study of risperidone in adults with autistic disorder and other pervasive developmental disorders. Arch Gen Psychiatry. 1998;55:633-41.

16. McDougle CJ, Kem DL, Posey DJ. Case series: use of ziprasidone for maladaptive symptoms in youths with autism. J Am Acad Child Adolesc Psychiatry. 2002;41:921-7.

17. Pellock JM, Appleton R. Use of new antiepileptic drugs in the treatment of childhood epilepsy. Epilepsia. 1999;40 Suppl $6: 29-38$.
18. Faught E. Pharmacokinetic considerations in prescribing antiepileptics drugs. Epilepsia. 2001;42 Suppl 4:19-23.

19. Yacubian EMT. Farmacocinética das drogas antiepilépticas. In: Yacubian EMT. Tratamento medicamentoso das epilepsias. São Paulo: Lemos Editorial; 1999.

20. Holmes GL, Stafstrom CE. The Epilepsies. In: Davis RB. Child and Adolescent Neurology. St. Louis: Mosby; 1998.

21. French JA, Gidal BE. Antiepileptic drug interactions. Epilepsia. 2000;41 Suppl 8:30-36.

22. Practice Parameter: a guideline for discontinuing antiepileptic drugs in seizure-free patients. Neurology. 1996;47(2):600-2.

23. Severo CMD, Nunes ML. Aspectos clínicos, tratamento e prognóstico de pacientes com síndrome de West. J Epilepsy Clin Neurophysiol. 2001;7(4):139-43.

24. Batista BHB, Nunes ML. Síndrome de West: definição, fisiopatologia, critérios diagnósticos e tratamento. Rev Med PUCRS. 2002;12:232-7.

25. Koul R, Chacko A, Ganesh A, Bulusu S, Al Riyami K. Vigabatrin associated retinal dysfunction in children with epilepsy. Arch Dis Child. 2001;85:469-73.

26. Curatolo $P$, Verdecchia $M$, Bombardieri R. Vigabatrin for tuberous sclerosis complex. Brain Dev. 2001;23:649-53.

27. Thijis J, Verhelst H, Van Coster R. Retrospective study of Topiramate in a pediatric population intractable epilepsy showing promising effects in the West syndrome patients. Acta Neurol Belg. 2001;101:171-6.

28. Suzuki Y. Zonisamide in West syndrome. Brain Dev. 2001;23: 658-61.

29. Toribe Y. High-dose vitamin B6 treatment in West syndrome. Brain Dev. 2001;23:654-7.

30. Takeuchi $Y$, Takano T, Abe J, Takikita S, Ohno M. Thyroropinreleasing hormone: role in the $\mathrm{B} 6$ treatment of West syndrome and related epileptic encephalopathies. Brain Dev. 2001;23: 668-76.

31. Hancock E, Cross H. Treatment of Lennox-Gastaut syndrome. Cochrane Database Syst Rev. 2003; (3):CD003277.

32. Dravet $C$, Bureau M. Benign myoclonic epilepsy in infancy. In: Roger J, Bureau M, Dravet C, Genton P, editors. Epileptic syndromes in infancy, childhood and adolescence. 3rd ed. London: John Libbey Ltd.; 2002. p. 69-79.

33. Fenichel GM. Neurologia pediátrica. Sinais e sintomas. 3rd ed. Rio de Janeiro: Revinter; 2000.

34. Yacubian EMT. Tratamento da epilepsia na infância. J Pediatr (Rio J). 2002; 78 Supl 1:19-27.

35. Bourgeois B. Drug treatment of benign focal epilepsies of childhood. Epilepsia. 2000;41(8):1057-8.

36. Engel J Jr. Seizures and epilepsy. Philadelphia: Davis Company; 1989. p. 410-442.

37. Zarate CA Jr, Tohen M, Narendran R, Tomassini EC, McDonald $\mathrm{J}$, Sederer $M$, et al. The adverse effect profile and efficacy of divalproez sodium compared with valproic acid: a pharmacoepidemiology study. J Clin Psychiatry. 1999;60:232-6.

38. Gausser TA. Topiramate. Epilepsia. 1999;40 Suppl 5:71-80.

39. McLean MJ, Gidal BE. Gabapentin dosing in the treatment of epilepsy. Clin Ther. 2003;25(5):1382-1406.

Corresponding author:

Gibsi P. Rocha

Departamento de Psiquiatria da FAMED - PUCRS

Hospital São Lucas da PUCRS

Av. Ipiranga, 6690

CEP 90610-000 - Porto Alegre, RS, Brazil

E-mail: GibsiR@aol.com 